\title{
Linfangiectasia intestinal e linfangite lipogranulomatosa em dois caninos
}

\author{
Intestinal lymphangiectasia with lipogranulomatous lymphangitis in two dogs
}

\author{
Marcia Regina da Silva Ilha ${ }^{1}$ Alexandre Paulino Loretti ${ }^{2}$ \\ Claudio Severo Lombardo de Barros $^{3}$
}

RESUMO

Relatam-se dois casos adicionais de linfangiectasia intestinal e linfangite lipogranulomatosa (LI/LL) em caninos. Sinais clínicos manifestados pelos animais afetados incluíam diarréia crônica, perda de peso, dificuldade respiratória e anorexia. À necropsia, a mucosa do intestino delgado apresentava-se pálida, macia e com aspecto aveludado mais evidente conferido por vilosidades esbranquiçadas, alongadas, mais visíveis e densamente aglomeradas formando tufos. $\mathrm{Na}$ borda mesentérica da serosa intestinal, havia lesões arredondadas, lisas, elevadas, firmes, brancacentas, de 1-3mm de diâmetro, que também acompanhavam os vasos linfáticos mesentéricos que estavam salientes e distendidos por material espesso e esbranquiçado. Carcaças em mau estado corporal, edema subcutâneo e efusões cavitárias também foram observados. Microscopicamente, havia acentuada ectasia dos vasos quilíferos das vilosidades intestinais associada à presença de lipogranulomas intramurais ou mesentéricos. No presente estudo, o diagnóstico definitivo de LI/LL foi realizado através do exame histológico do intestino delgado e mesentério associado. Desconhece-se a prevalência dessa enfermidade em caninos no Brasil.

Palavras-chave: doença intestinal crônica, enteropatia com perda protéica, vasos linfáticos, intestino delgado, diarréia.

\section{ABSTRACT}

Two additional cases of intestinal lymphangiectasia with lipogranulomatous lymphangitis $(I L / L L)$ in dogs are described. Clinical signs in the affected animals included chronic diarrhea, weight loss, labored breathing and anorexia. At necropsy, the mucosa of the small intestine was pale, soft and had numerous white, elongated villi clumped together in tufts giving the surface of the intestinal mucosa a pronounced velvety pattern. White, round, smooth, raised, firm, pinpoint lesions, varying from 1-3mm of diameter, were observed on the serosal surface of the small intestine on its mesenteric border and along prominent mesenteric lymphatic vessels distended with thick, chalky white paste. Thin carcasses. subcutaneous edema and cavitary effusions were also observed. Microscopically, the lacteals of the villi of the small intestine were markedly dilated and there were many intramural and mesenteric lipogranulomas. In the present study, histological evaluation of the small intestine and its attached mesentery was necessary to confirm the diagnosis of $I L / L L$. The prevalence of this entity in dogs in Brazil remains to be determined.

Key words: chronic enteric disease, protein-losing enteropathy, lymph vessels, small intestine, diarrhea.

\section{INTRODUÇÃO}

A linfangiectasia intestinal (LI) revela-se como a mais comum das enteropatias associadas à má absorção e perda de proteínas em caninos (FINCO et al., 1973, OLSON \& ZIMMER, 1978, VAN KRUININGEN et al., 1984, FOSSUM et al., 1987, BEZEK et al., 1992, BARKER et al., 1993). Caracteriza-se pela dilatação anormal dos vasos linfáticos das vilosidades intestinais (vasos quilíferos) e linfáticos da mucosa e submucosa do intestino. Raças caninas mais predispostas ao

${ }^{1}$ Médico Veterinário, Mestre, Rua Paissandu, 385, apto. 201, 22210-080, Flamengo, Rio de Janeiro, RJ, Brasil. E-mail: ilha76@ hotmail.com. Autor para correspondência.

${ }^{2}$ Médico Veterinário, Mestre, Professor Assistente 3, Setor de Patologia Veterinária, Departamento de Patologia Clínica Veterinária, Faculdade de Medicina Veterinária, Universidade Federal do Rio Grande do Sul (UFRGS), Porto Alegre, RS, Brasil.

${ }^{3}$ Médico Veterinário, PhD., Professor Titular, Seção de Patologia Veterinária, Departamento de Patologia, Universidade Federal de Santa Maria (UFSM), Santa Maria, RS, Brasil. 
desenvolvimento dessa condição incluem a Basenji, Norwegian Lundehund, Yorkshire Terrier, Norwegian Spitz e soft-coated Wheaten Terrier (BARKER et al., 1993). Clinicamente, os animais afetados apresentam diarréia crônica com fezes semi-sólidas ou aquosas, amareladas ou sanguinolentas, além de esteatorréia e flatulência. Vômitos esporádicos, emagrecimento progressivo, letargia, anorexia e intolerância ao exercício também são observados. Os animais podem apresentar ainda edema do tecido subcutâneo afetando as porções ventrais do corpo e extremidades dos membros (edema de declive), efusões cavitárias, dificuldade respiratória e tosse (OLSON \& ZIMMER, 1978; VAN KRUININGEN et al., 1984; BEZEK et al., 1992; BURROWS et al., 1997). A doença é usualmente insidiosa e o curso clínico varia de semanas a meses (VAN KRUININGEN et al., 1984; BURROWS et al., 1997). Alterações laboratoriais descritas para essa enfermidade incluem hipoproteinemia, hipoglobulinemia, linfopenia, hipocalcemia e hipocolesterolemia (FINCO et al., 1973; OLSON \& ZIMMER, 1978; BEZEK et al., 1992; BARKER et al., 1993; BURROWS et al., 1997). Linfopenia é um achado hematológico que distingue a LI das demais enteropatias associadas à perda protéica em cães. À necropsia, a mucosa intestinal apresenta as vilosidades brancas e proeminentes conferindo a essa o aspecto de um tapete. Pequenos nódulos brancos, semelhantes a sabão, irregulares ou redondos, de $1 \mathrm{~mm}$ a $1 \mathrm{~cm}$ de diâmetro, são encontrados na serosa do intestino delgado, principalmente na sua inserção com o mesentério, afetando em especial o jejuno. Há também dilatação dos linfáticos da serosa e mesentério associado. Histologicamente, há marcada ectasia dos vasos quilíferos das vilosidades e dos linfáticos da submucosa, muscular e subserosa intestinal. Linfangite lipogranulomatosa (LL) é uma lesão que pode acompanhar a LI. Caracteriza-se pela formação de lipogranulomas ricos em macrófagos contendo lipídios localizados na luz dos linfáticos da mucosa, muscular, subserosa e mesentério e correspondem à intensa reação granulomatosa frente ao vazamento de material saponificado proveniente de vasos linfáticos sobrecarregados de quilo que se romperam (FINCO et al., 1973; OLSON \& ZIMMER, 1978; VAN KRUININGEN et al., 1984; BARKER et al., 1993; BURROWS et al., 1997). Doença semelhante também tem sido descrita em bovinos e humanos (BEZEK et al., 1992).

Diversos estudos abordando os aspectos clínico-patológicos, radiográficos e ultra-sonográficos da LI/LL têm sido realizados por diversos autores
(FINCO et al., 1973; VAN KRUININGEN et al., 1984; KULL et al., 2001). No Brasil, no entanto, os estudos a respeito dessa enfermidade são escassos (HAGIWARA et al., 1982; HIGA et al., 2001). Desconhece-se a prevalência dessa condição nas populações caninas locais trazidas aos diversos estabelecimentos veterinários destinados ao atendimento de animais de guarda e companhia em nosso país.

O presente estudo tem como objetivo descrever os aspectos clínicos e patológicos de dois casos adicionais de linfangiectasia intestinal associada à linfangite lipogranulomatosa em caninos.

\section{MATERIAL E MÉTODOS}

Durante os anos de 1999 e 2000, dois caninos foram trazidos à Seção de Patologia Veterinária da Universidade Federal de Santa Maria (UFSM), Santa Maria, RS, (canino 1) e ao Setor de Patologia Veterinária da Universidade Federal do Rio Grande do Sul (UFRGS), Porto Alegre, RS (canino 2) para necropsia. O histórico e os sinais clínicos da doença foram obtidos junto aos veterinários responsáveis e proprietários. O canino 1 foi submetido à eutanásia em função do prognóstico desfavorável da enfermidade enquanto que o canino 2 morreu durante laparotomia exploratória. Fragmentos de diversos órgãos e o encéfalo foram colhidos à necropsia, fixados em formol a $10 \%$ e processados rotineiramente para exame histológico.

\section{RESULTADOS}

O canino 1 era uma fêmea, de 7 anos de idade, sem raça definida, que tinha disfunção respiratória, observada inicialmente há 6 meses, caracterizada por dificuldade respiratória, taquipnéia e estertores hidroaéreos, e que apresentava também taquicardia, pulso fraco e anasarca. O diagnóstico clínico presuntivo foi insuficiência cardíaca congestiva. O canino 2 era um macho, de 9 meses de idade, da raça Fila Brasileiro, que apresentava diarréia, anorexia, caquexia, dispnéia, acentuado aumento de volume abdominal e mucosas pálidas. A suspeita clínica era de dilatação-torção gástrica. À necropsia, ambas as carcaças estavam em mau estado corporal. A principal lesão macroscópica foi observada no intestino delgado (ID) e consistia em mucosa pálida, macia e de aspecto aveludado conferido por vilosidades alongadas, brancacentas e que formavam tufos brilhantes e salientes (Figura 1). No canino 1, 


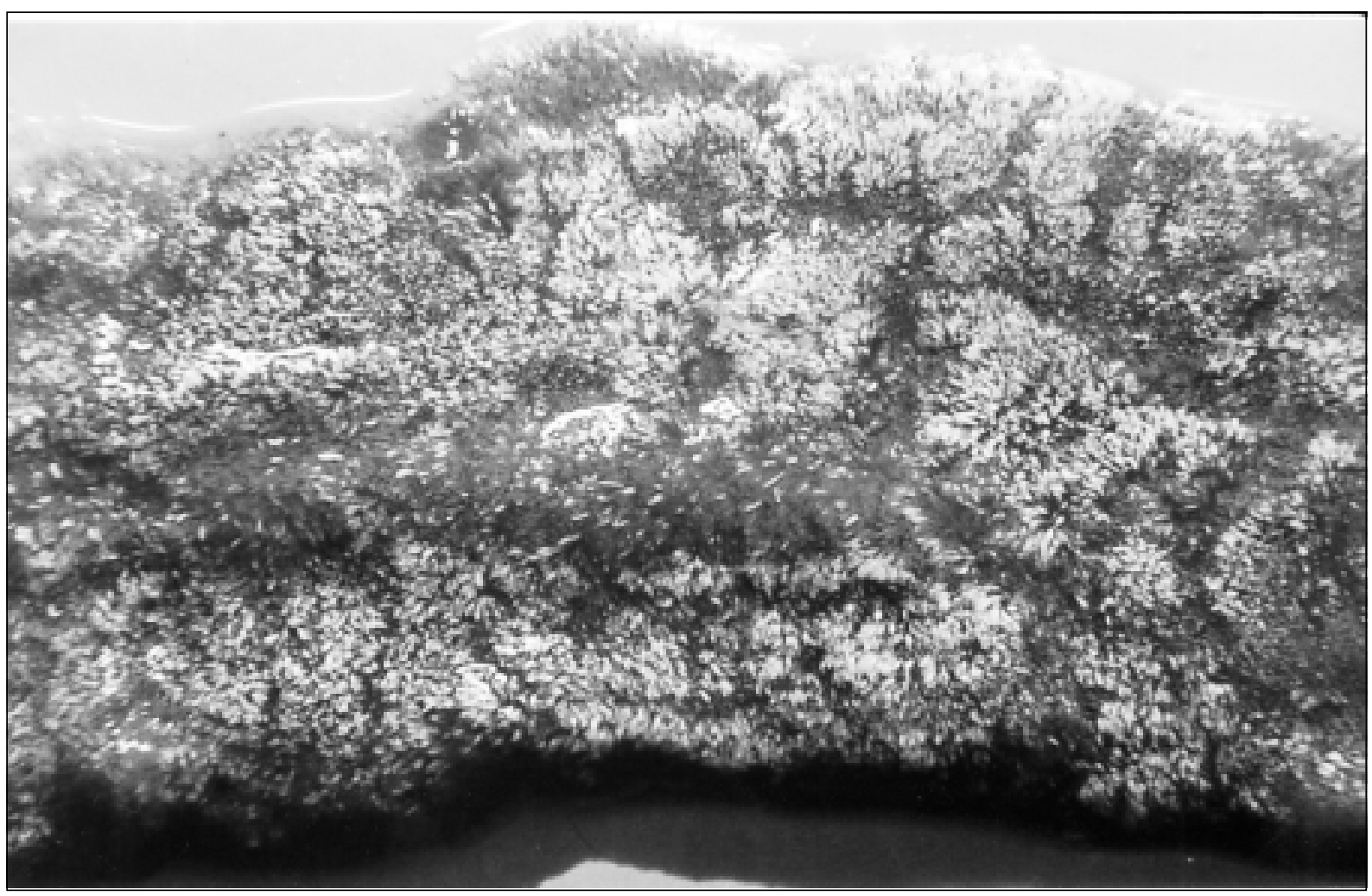

Figura 1 - Linfangiectasia intestinal/linfangite lipogranulomatosa. Canino 2. A mucosa do intestino delgado apresentava-se pálida, macia e com aspecto aveludado mais evidente que o normal, conferido por vilosidades esbranquiçadas, alongadas, bastante visíveis e densamente aglomeradas formando tufos.

essa lesão foi observada principalmente no terço médio do ID enquanto que no canino 2 essa lesão era difusa e afetava de forma homogênea todos os segmentos da superfície mucosa do ID. Na serosa do ID, havia diminutas lesões arredondadas, lisas, elevadas, firmes, brancacentas, de 1-3mm de diâmetro, localizadas no ponto de inserção do mesentério à serosa do ID e ao longo do mesentério (Figura 2). Os vasos linfáticos da superfície serosa do ID e do mesentério associado às alças do intestino delgado estavam dilatados e apareciam sob a forma de estrias lineares ou tortuosas, salientes e preenchidas por material espesso e esbranquiçado. Havia também acúmulo de líquido translúcido e límpido nas cavidades corporais de ambos os cães (ascite e hidrotórax). Adicionalmente, o canino 1 apresentava acentuado edema do tecido subcutâneo ventral que se estendia da região mentoniana ao último par de glândulas mamárias e membro posterior direito além de espessamento edematoso da parede do estômago. Outras lesões macroscópicas observadas no canino 2 incluíam atelectasia compressiva dos lobos pulmonares diafragmáticos, sinais externos de desidratação e acentuada distensão do estômago que não apresentava conteúdo alimentar algum e estava preenchido por grande quantidade de gás. Não foram observadas alterações morfológicas no sistema cardiovascular. Histologicamente, havia acentuada dilatação e distorção dos vasos linfáticos centrais das vilosidades intestinais (vasos quilíferos) (Figura 3). As vilosidades do ID tinham o contorno arredondado e atenuado. Havia moderado infiltrado mononuclear na lâmina própria da mucosa intestinal associado à ectasia dos vasos linfáticos da submucosa e subserosa do intestino delgado. A luz dos vasos linfáticos subserosais estavam ocluídos por lipogranulomas que se caracterizavam pela formação de aglomerados de macrófagos finamente vacuolizados ou espumosos e com o citoplasma preenchido por material lipídico amorfo (lipófagos).

\section{DISCUSSÃO}

No presente estudo, o diagnóstico de LI/ LL foi baseado no histórico, sinais clínicos e lesões

Ciência Rural, v.34, n.4, jul-ago, 2004. 


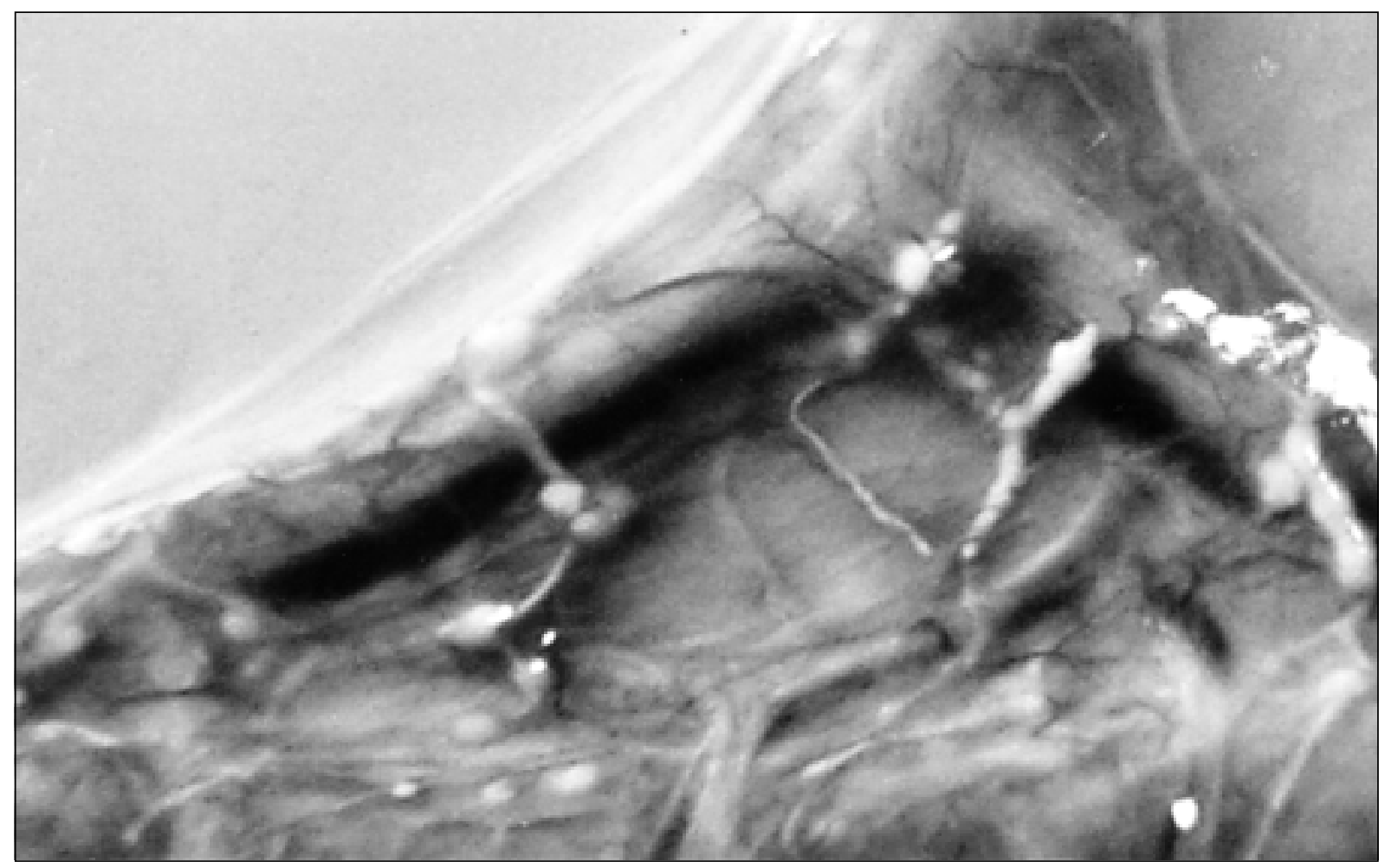

Figura 2 - Linfangiectasia intestinal/linfangite lipogranulomatosa. Canino 2. Na borda mesentérica da serosa intestinal há lesões arredondadas, lisas, elevadas, firmes, brancacentas, de 1-3 mm de diâmetro, que também acompanham vasos linfáticos salientes e esbranquiçados ao longo do mesentério. Histologicamente, esses nódulos correspondiam a lipogranulomas.

macro e microscópicas. O diagnóstico definitivo de LI/LL foi realizado através do exame histológico do intestino delgado e mesentério associado. Os pontos brancos observados na serosa do ID e distribuídos ao longo da cadeia linfática mesentérica correspondiam histologicamente à LL com a formação de lipogranulomas. Deve ser mencionado que lipogranulomas nem sempre estão presentes nos casos de LI em caninos. Acredita-se que os lipogranulomas se formem a partir da reação inflamatória do tipo corpo estranho, rica em macrófagos, que se desenvolve frente ao extravasamento dos lipídios do quilo através da parede de vasos quilíferos ectásicos ou rompidos e não devem ser considerados como a causa primária da obstrução linfática como tem sido sugerido por alguns autores (VAN KRUININGEN et al., 1984; KULL et al., 2001). Mucosa do intestino delgado atapetada e linfáticos mesentéricos esbranquiçados e salientes são lesões observadas nos casos de LI/LL e que devem ser diferenciadas macroscopicamente da dilatação linfática fisiológica observada nas vilosidades intestinais e linfáticos do mesentério em anexo associada à digestão e absorção de alimentos imediatamente após as refeições.

Uma forma primária e congênita da LI, observada em animais jovens, tem sido associada à presença de um número reduzido de linfáticos na mucosa intestinal (malformações congênitas do sistema linfático p.ex. hipoplasia dos vasos linfáticos intestinais e mesentéricos). Uma forma secundária e adquirida dessa doença também tem sido descrita sendo atribuída à hipertensão venosa (drenagem linfática anormal acompanhada de maior produção de linfa intestinal resultante de aumento da pressão hidrostática venosa nos casos de insuficiência cardíaca congestiva) (BURROWS et al., 1997) ou a lesões obstrutivas afetando o sistema linfático p.ex. infiltração ou obliteração inflamatória dos linfáticos intestinais, traumatismo, fibrose ou neoplasia e obstrução do fluxo no ducto torácico (OLSON \& ZIMMER, 1978; BURROWS et al., 1997). Nos casos aqui descritos, fatores predisponentes e possíveis causas de LI/LL não foram identificados. 


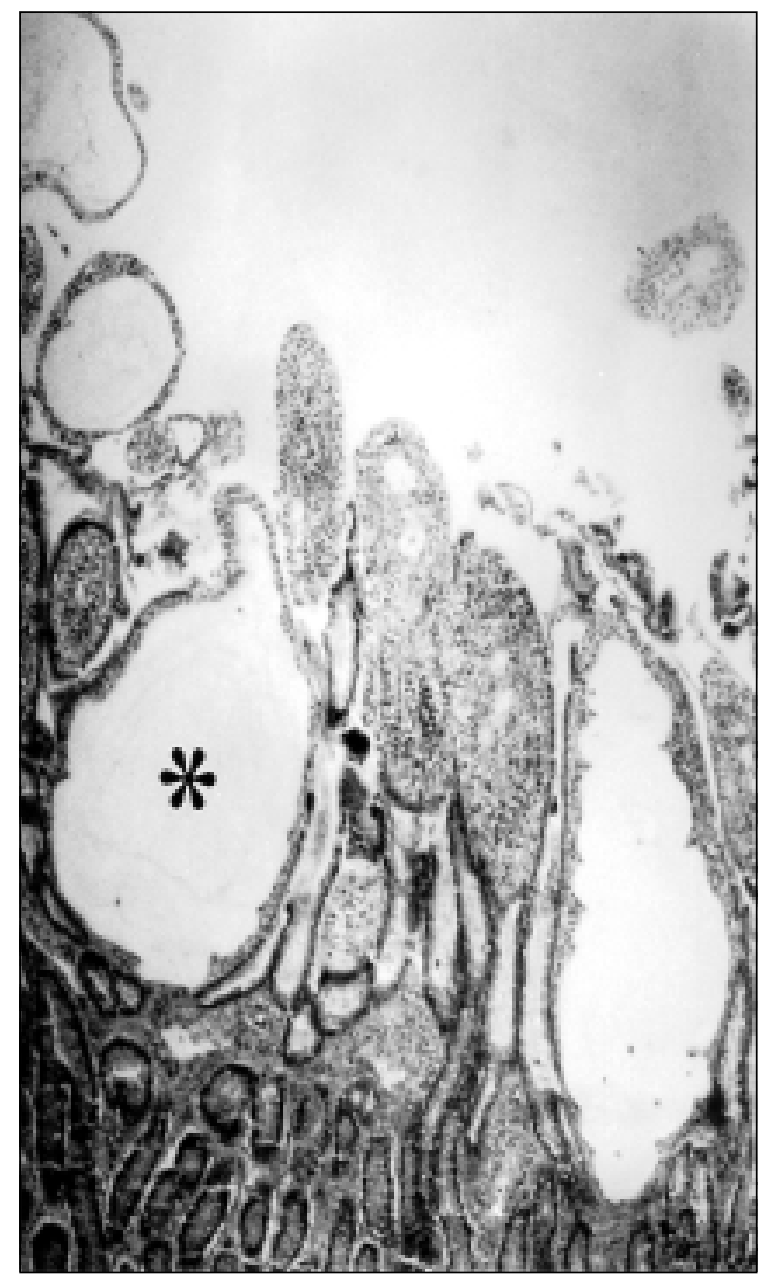

Figura 3 - Linfangiectasia intestinal/linfangite lipogranulomatosa. Canino 1. Acentuada ectasia dos vasos lactíferos das vilosidades intestinais (asterisco). H.-E. Obj. 10X.

Alguns mecanismos patogenéticos têm sido apontados como responsáveis pelo desenvolvimento do quadro de hipoproteinemia observado nos casos de LI/LL como os que foram aqui descritos. Em condições fisiológicas, há perda diária de proteínas plasmáticas no trato gastrintestinal em conseqüência do extravasamento de proteínas da lâmina própria no topo das vilosidades que corresponde ao local onde usualmente ocorre a descamação de células epiteliais. No lúmen intestinal, grande parte das proteínas extravasadas é reduzida a aminoácidos e então reabsorvida (OLSON \& ZIMMER, 1978; BURROWS et al., 1997). A perda entérica de proteínas é acelerada naquelas doenças que rompem a barreira mecânica oferecida pela mucosa intestinal ou que interferem na drenagem dos linfáticos intestinais (BURROWS et al., 1997). Nesses casos, os linfáticos intestinais transportam os produtos da absorção da gordura da mucosa intestinal para o ducto torácico e circulação venosa (BURROWS et al., 1997). Alterações na drenagem linfática, presumivelmente causadas pela obstrução do fluxo linfático-venoso normal, levam à estase do quilo nos vasos quilíferos dos vilos intestinais e linfáticos da parede do intestino delgado e mesentério (BURROWS et al., 1997). A liberação de linfa na luz intestinal através do extravasamento de linfa por meio de vasos quilíferos acentuadamente distendidos ou rompidos promove a perda dos constituintes normais do quilo que incluem as proteínas plasmáticas, linfócitos e lipídios (quilomicras) (OLSON \& ZIMMER, 1978). Nas enteropatias com perda protéica, a hipoproteinemia ocorre quando a perda de proteínas excede a síntese compensatória uma vez que a concentração de proteínas no quilo corresponde a $20-40 \%$ do total de proteínas encontradas no plasma (OLSON \& ZIMMER, 1978; BURROWS et al., 1997). Os derrames cavitários associados à linfangiectasia observados durante a necropsia são, usualmente, transudatos que se formam devido a um quadro de hipoproteinemia, como nos casos aqui estudados. Todavia, ascite quilosa também é ocasionalmente observada e ocorre aparentemente devido ao extravasamento do fluido linfático quiloso de vasos linfáticos da serosa intestinal ou mesentério que estão ectásicos ou se romperam (HIGA et al., 2001). Hidrotórax quiloso também tem sido observado em alguns pacientes e está associado a defeitos no transporte linfático-venoso do quilo na cavidade torácica para a circulação sistêmica (FOSSUM et al., 1987).

O quadro clínico observado na LI/LL não é específico mas comum a diversas enfermidades entéricas e não-entéricas que afetam os cães. Sugere-se que casos dessa doença já tenham passado despercebidos em outras ocasiões na rotina dos estabelecimentos clínico-veterinários para pequenos animais uma vez que essa condição é facilmente confundida com aquelas enfermidades que, de forma semelhante, provocam emagrecimento progressivo, diarréia e formação de efusões cavitárias. No diagnóstico diferencial da LI/LL devem ser incluídas causas não-entéricas de hipoproteinemia tais como insuficiência hepática 
e doenças renais (BURROWS et al., 1997), e insuficiência cardíaca congestiva (OLSON \& ZIMMER, 1978). Outras doenças que afetam os intestinos delgado e grosso também devem ser consideradas p.ex. (a) enterites crônicas enterite linfoplasmocitária de etiologia multifatorial p.ex. aquelas associadas ao crescimento bacteriano excessivo, aquelas ligadas à alergia alimentar (enteropatia sensível ao glúten, trigo ou lactose) ou as de natureza idiopática, (b) enterite granulomatosa regional, (c) enterite eosinofílica, (d) enteropatia imunoproliferativa dos cães da raça Basenji, (e) atrofia vilosa idiopática, (f) endoparasitismo intestinal, (g) neoplasias intestinais caquetizantes p.ex. linfossarcomas gastrintestinais epiteliotrópicos, adenocarcinomas, leiomiossarcomas, (h) enterites e colites infecciosas tais como a ficomicose (pitiose), histoplasmose, micobacteriose, prototecose, (i) má nutrição e (j) insuficiência pancreática exócrina acompanhada ou não de doença malabsortiva da mucosa intestinal (BEZEK et al., 1992; BURROWS et al., 1997; RECH \& GRAÇA, 2002). Deve-se levar em consideração o fato de que a LI ocorre com maior freqüência em cães adultos (FINCO et al., 1973; VAN KRUININGEN et al., 1984; FOSSUM et al., 1987; BEZEK et al., 1992), faixa etária em que esses animais são mais propensos ao desenvolvimento de doenças crônicas intestinais e não-intestinais.

No presente trabalho, LI/LL foi confundida clinicamente com insuficiência cardíaca congestiva em um dos casos (canino 1) em razão da presença de edemas cavitários e dificuldade respiratória. Entretanto, não foram observadas alterações morfológicas no coração desse animal. Casos semelhantes a esse podem ser diagnosticados de forma equivocada quando baseados exclusivamente no histórico e exame clínico e naquelas situações em que exames complementares não são realizados. O diagnóstico definitivo da linfangiectasia intestinal é estabelecido através do exame histológico de biópsias intestinais associado aos achados clínicos, radiográficos e laboratoriais sugestivos de enteropatia associada à perda protéica. De um modo geral, a escassez de recursos diagnósticos nos estabelecimentos clínico-veterinários do país aliada aos recursos financeiros insuficientes dos clientes limita ou inviabiliza o exame pormenorizado dos pacientes tornando o diagnóstico da LI/LL uma tarefa difícil para o clínico veterinário.

\section{AGRADECIMENTOS}

Os autores agradecem a assistência técnica do Sr. João Francisco Nunes [Técnico em Histopatologia do Laboratório Regional de Diagnóstico, Universidade Federal de Pelotas (UFPel), Pelotas, RS] na confecção dos cortes histológicos e do Prof. David Driemeier [Setor de Patologia Veterinária, Departamento de Patologia Clínica Veterinária, Faculdade de Veterinária, Universidade Federal do Rio Grande do Sul (UFRGS), Porto Alegre, RS] na realização da foto microscópica.

\section{REFERÊNCIAS BIBLIOGRÁFICAS}

BARKER, I.K.; VAN DREUMEL, A.A.; PALMER, N. The alimentary system. In: JUBB, K.V.F.; KENNEDY, P.C.; PALMER, N. Pathology of domestic animals. 4.ed. San Diego : Academic, 1993. V.2. Cap.1, p.1-318.

BEZEK, D.M.; PORTE, K.B.; DUNSTAN, R. Minimal clinical signs associated with lipogranulomatous lymphangitis and intestinal lymphangiectasia in a dog. J Am Anim Hosp Assoc, v.28, n.5, p.425-429, 1992.

BURROWS, C.F.; BATT, R.M.; SHERDING, R.G. Afecções do intestino delgado. In: ETTINGER, S.J.; FELDMAN, E.C. Tratado de medicina interna veterinária - Moléstias do cão e do gato. 4. ed. São Paulo : Manole, 1997. V.2. Cap.104, p.1618-1705.

FINCO, D.R. et al. Chronic enteric disease and hypoproteinemia in 9 dogs. J Am Vet Med Assoc, v.163, n.3, p.262-271, 1973

FOSSUM, T.W. et al. Intestinal lymphangiectasia associated with chylothorax in two dogs. J Am Vet Med Assoc, v.190, n.1, p.6164, 1987.

HAGIWARA, M.K.; IWASAKI, M.; ALVARENGA, J. Linfangiectasia intestinal em cão. In: CONGRESSO BRASILEIRO DE MEDICINA VETERINÁRIA, 18., 1982, Camboriú, SC. Anais... Camboriú : CONBRAVET, 1982. V. 1, p.492.

HIGA, A.C. et al. Linfangiectasia em cão: relato de caso. In: CONGRESSO BRASILEIRO DE MEDICINA VETERINÁRIA, 28., 2001, Salvador, BA. Livro de resumos... Salvador: CONBRAVET, 2001. p.83.

KULL, P.A. et al. Clinical, clinicopathologic, radiographic, and ultrasonographic characteristics of intestinal lymphangiectasia in dogs: 17 cases (1996-1998). J Am Vet Med Assoc, v.219, n.2, p.197-202, 2001.

OLSON, N.C.; ZIMMER, J.F. Protein-losing enteropathy secondary to intestinal lymphangiectasia in a dog. J Am Vet Med Assoc, v.173, n.3, p.271-274, 1978. 
RECH R.R., GRAÇA, D.L. Pitiose em um cão. Santa Maria : PPGMV, 2002. 14p.[Seminário apresentado ao Programa de Pósgraduação em Medicina Veterinária (PPGMV)].
VAN KRUININGEN, H.J. et al. Lipogranulomatous lymphangitis in canine intestinal lymphangiectasia. Vet Pathol, v.21, n.4, p.377-383, 1984.

Ciência Rural, v.34, n.4, jul-ago, 2004. 